\title{
Severe Hypertriglyceridemia due to a novel p.Q240H mutation in the Lipoprotein Lipase gene
}

\author{
Angela Ganan Soto ${ }^{1}$, Adam McIntyre², Sungeeta Agrawal ${ }^{1}$, Shara R. Bialo ${ }^{1}$, Robert A. Hegele ${ }^{2}$ \\ and Charlotte M. Boney ${ }^{3^{*}}$
}

\begin{abstract}
Background: Lipoprotein Lipase (LPL) deficiency is a rare autosomal recessive disorder with a heterogeneous clinical presentation. Several mutations in the LPL gene have been identified to cause decreased activity of the enzyme.

Findings: An 11-week-old, exclusively breastfed male presented with coffee-ground emesis, melena, xanthomas, lipemia retinalis and chylomicronemia. Genomic DNA analysis identified lipoprotein lipase deficiency due to compound heterozygosity including a novel p.Q240H mutation in exon 5 of the lipoprotein lipase (LPL) gene. His severe hypertriglyceridemia, including xanthomas, resolved with dietary long-chain fat restriction.

Conclusions: We describe a novel mutation of the LPL gene causing severe hypertriglyceridemia and report the response to treatment. A review of the current literature regarding LPL deficiency syndrome reveals a few potential new therapies under investigation.
\end{abstract}

Keywords: Chylomicronemia, Triglyceride, Lipoprotein lipase deficiency

\section{Findings}

Exogenous lipid metabolism involves packaging of dietary fat into chylomicrons in the small intestine, which are later transported to the bloodstream. The initial step of endogenous lipid metabolism involves the hydrolysis of chylomicrons by lipoprotein lipase (LPL) [1]. LPL deficiency is a rare autosomal recessive disorder with a prevalence of 1 in 1,000,000 in the United States and higher in other world regions, like Quebec, Canada due to a founder effect [2]. The clinical presentation can include moderate or severe hypertriglyceridemia in affected homozygotes or compound heterozygotes, while simple heterozygote carriers often have normal lipids [3]. Clinical features include eruptive xanthomas, abdominal pain, hepato-splenomegaly, lower gastrointestinal bleeding, recurrent pancreatitis, or lipemia retinalis [4]. Dietary fat restriction is the cornerstone of treatment, and gene therapy trials are ongoing [5].

\footnotetext{
* Correspondence: charlotte.boneymd@baystatehealth.org

${ }^{3}$ Baystate Children's Hospital, 759 Chestnut Ave S584, Springfield, MA, USA

Full list of author information is available at the end of the article
}

\section{Case report}

We report the case of an 11-week-old male of Puerto Rican descent who presented to the emergency department with coffee-ground emesis, melena and a papular rash. He was born full term to healthy, nonconsanguineous parents with a birth weight of $8 \mathrm{lb} 4 \mathrm{oz}$ and was exclusively breast-fed. He had 4-5 episodes of coffeeground emesis, one episode of melena and a papular rash (Fig. 1) that spread from his extremities to his trunk over the course of 3 weeks. CBC revealed a hematocrit of $17 \%$ and his blood was grossly lipemic. A random lipid panel showed triglycerides (TG) of 43,980 mg/dl.

The physical exam was notable for a well-appearing infant with diffuse $2 \mathrm{~mm}$ yellow papules consistent with eruptive xanthomas and lipemia retinalis on fundoscopic exam. Fasting lipid profile revealed total cholesterol $768 \mathrm{mg} / \mathrm{dl}$, TG 37,695 mg/dl, and HDL $<10 \mathrm{mg} / \mathrm{dl}$. Breast-feeding was discontinued and he was placed on Enfaport Lipil, a formula with $84 \%$ of fat content from medium-chain triglycerides (MCT) and $16 \%$ from long-chain fats. A repeat lipid profile one month after the formula change revealed dramatic improvement in TG (Table 1). Two months after 


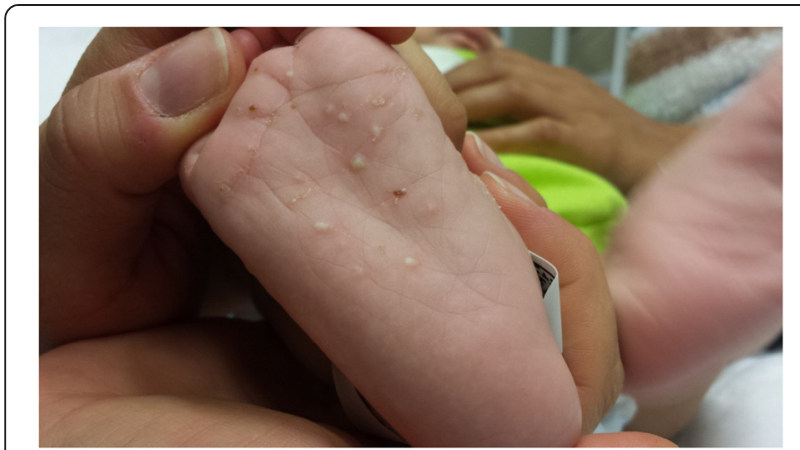

Fig. 1 Eruptive xanthomas on the right sole

treatment, xanthomas and lipemia retinalis resolved; weight gain and linear growth were normal. We hypothesized that this child had an autosomal recessive mutation in the $L P L$ gene.

\section{Methods}

Ethics, consent and permission:Approval was obtained from the Western University Ethics Review Board protocol 07920E and informed consent was obtained from both parents. The parents gave their consent to publish this case.

Genomic DNA was isolated from whole blood using Puregene DNA isolation kit (Gentra Systems, QIAGEN Inc, Mississauga, ON, Canada). PCR amplifications were performed using primers covering the coding regions and $\sim 100$ bp of intron-exon boundaries of the LPL gene as described previously [3]. Bi-directional Sanger sequencing was performed using established conditions [3] on an ABI 3730 DNA Analyzer (Applied Biosystems, Foster City, CA, USA). DNA sequences were analyzed using SeqScape v2.6 (Applied Biosystems, Foster City, CA, USA).

\section{Results and discussion}

We found that the proband was a compound heterozygote for one novel and one reported mutation within exon 5 of the LPL gene (Fig. 2). The first mutation p.G215E was a heterozygous transition c.644G $\rightarrow$ A, resulting in a substitution of glycine to glutamic acid at amino acid 215 (identical to residue 188 in the mature protein). This mutation has been previously reported to cause LPL deficiency [6]. The second, novel mutation
p.Q240H was a heterozygous transversion c.721G $\rightarrow$ T, causing an amino acid substitution of glutamine to histidine at residue 240 (identical to residue 213 in the mature protein). In silico software programs PolyPhen 2 and SIFT both predicted that this mutation was probably damaging. Both parents' DNA samples were sequenced: the LPL p.Q240H mutation was found in the father and the p.G215E mutation was found in the mother.

LPL plays a role in multiple stages of lipid metabolism, including hydrolysis of chylomicrons. LPL is primarily synthesized by myocytes and adipocytes and recent studies have identified glycosylphosphatidylinositol-anchored high-density lipoprotein-binding protein 1 (GPIHBP1) as the molecule responsible for transporting LPL to the capillary lumen [7]. LPL deficiency is a rare autosomal recessive disorder caused by decreased LPL activity due to mutations in the $L P L$ gene [2]. The $L P L$ gene is located on chromosome 8p21.3 and contains 10 exons, spanning $\sim 30 \mathrm{~kb}$ and encodes a mature protein of 448 amino acids [8]. Most mutations are found in exons 4, 5 and 6 and although missense mutations are more common, nonsense, frameshift, insertion, deletion and duplication mutations have also been described [9]. The mutation in this patient expands the spectrum of known pathogenic LPL mutations to more than 150 . It also occurs in a region of the protein that has to date been relatively bereft of reported mutations. The involvement of amino acid residue 240 also highlights the functional importance of the local domain in lipolysis of triglyceride-rich lipoproteins.

To date, genotype-phenotype correlations have not been identified $[2,10]$. Patients who are homozygous or compound heterozygotes can present with marked hypertriglyceridemia. Heterozygote patients can have normal or mildly elevated TG levels [3]. Both parents of our patient are heterozygous carriers of LPL gene mutations and had normal lipids.

The clinical manifestations of LPL deficiency are heterogeneous. Eruptive xanthomas appear mostly on shoulders, buttocks and extensor surfaces of the limbs when the TG levels exceed $2000 \mathrm{mg} / \mathrm{dl}$ [11]. Lipemia retinalis involving the peripheral vessels can be seen with TG levels over $2,500 \mathrm{mg} / \mathrm{dl}$ and as the levels increase, the damage extends to the posterior

Table 1 Plasma lipid levels of the proband at baseline and after 1 month of dietary fat restriction, and both parents

\begin{tabular}{|c|c|c|c|c|c|}
\hline \multirow[t]{2}{*}{ Lipid profile } & \multicolumn{3}{|l|}{ Proband } & \multirow[t]{2}{*}{ Mother } & \multirow[t]{2}{*}{ Father } \\
\hline & Baseline (non-fasting) & Baseline (fasting) & After dietary change & & \\
\hline TG (mg/dl) & 43,980 & 37,695 & 375 & 87 & 78 \\
\hline $\mathrm{TC}(\mathrm{mg} / \mathrm{dl})$ & 761 & 768 & 98 & 190 & 127 \\
\hline $\mathrm{HDL}(\mathrm{mg} / \mathrm{dl})$ & 37 & $<10$ & 21 & 43 & 41 \\
\hline LDL (mg/dl) & Unable to measure & Unable to measure & 2 & 130 & 70 \\
\hline
\end{tabular}




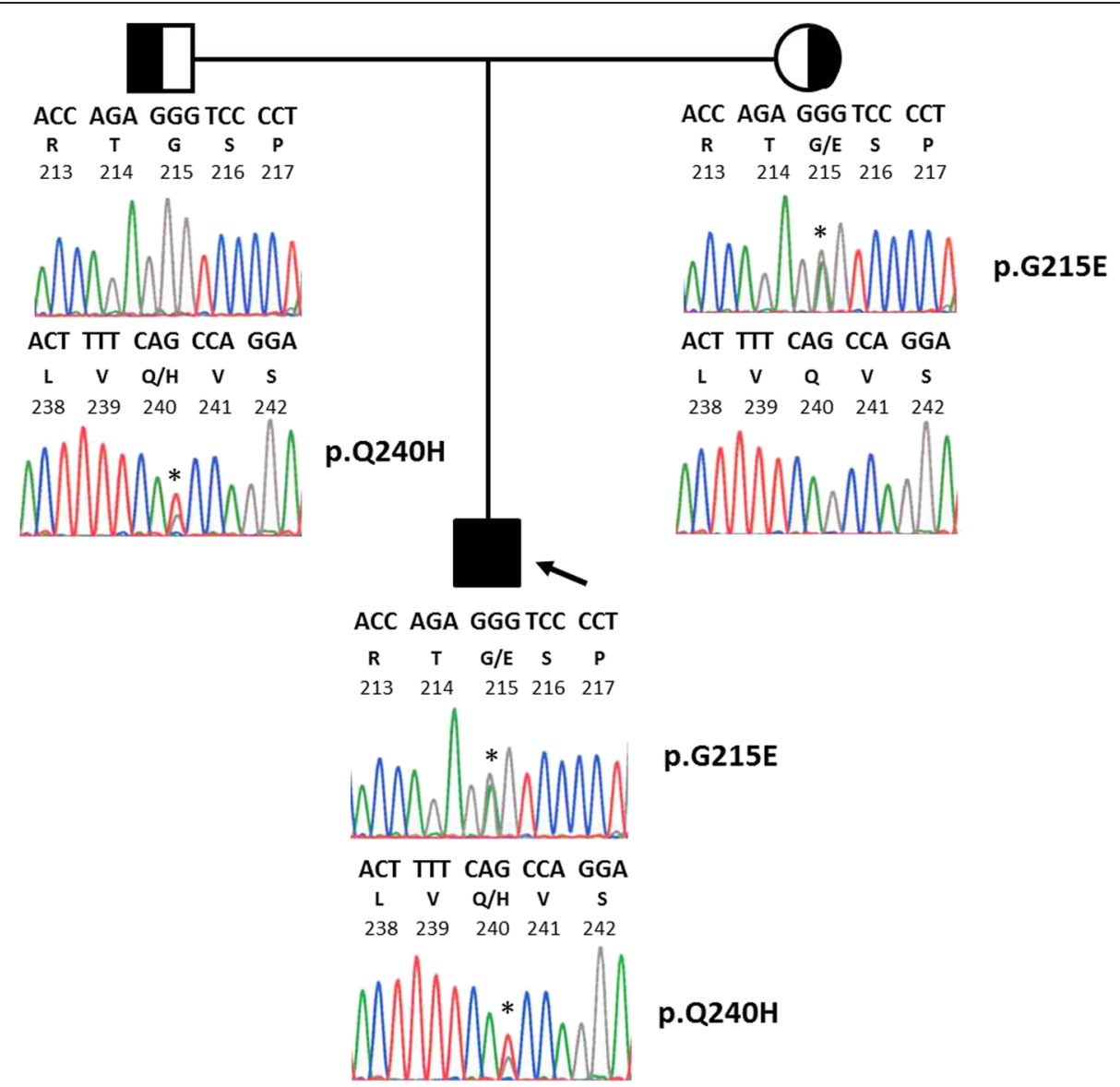

Fig. 2 Segregation of LPL mutations in index family. Pedigree structure and DNA sequence electropherogram tracings of the LPL gene in the vicinity of codons 215 and 240 for each family member are shown. Three letter nucleotide sequences, single letter amino acid codes, and codon numbers corresponding to amino acid residues are indicated. Asterisks show heterozygosity at the specific amino acid position: the father is a simple heterozygote for the p.Q240H mutation, the mother is a simple heterozygote for the p.G215E mutation and the proband is a compound heterozygote for both mutations

pole [12]. Abdominal pain and gastrointestinal hemorrhage have been attributed to hyperviscosity secondary to elevated TG [13]. Pancreatitis is common in these patients and risk increases with TG levels over $1,000 \mathrm{mg} / \mathrm{dl}$ [14]. Therefore, the goal of therapy is to decrease TG levels $<1,000 \mathrm{mg} / \mathrm{dl}[15]$.

Dietary restriction remains the cornerstone of treatment and fat supplements using MCT are useful since they are absorbed directly into the portal vein [15]. Long-term data on patients with LPL deficiency are limited but show normal linear growth and puberty despite dietary fat restriction [4]. Even with recurrent pancreatitis, this population does not demonstrate a high mortality rate [16]. Satisfactory TG levels can be difficult to achieve with diet restriction alone. Drug therapy using gemfibrozil, omega-3 fatty acids and orlistat may decrease TG levels when combined with a fat-restricted diet however, the use of these drugs is controversial [3, 17, 18]. Therapy involving intramuscular introduction of a gain-of-function variant of the
LPL gene is approved in Europe, although is costly and has only a transient effect [5]. A promising treatment approach currently under investigation is orallyadministered diacylglycerol O-acyltransferase 1 (DGAT1) inhibitors targeting DGAT1, which mediates triglyceride synthesis during dietary fat absorption [19].

Our patient is a compound heterozygote who has a novel p.Q240H mutation in exon 5 of the $L P L$ gene causing severe hypertriglyceridemia. Although his TG levels are much improved with MCT-based formula, the challenge will be maintaining those levels with dietary fat restriction as table foods are introduced and he grows through childhood.

\section{Competing interests}

Angela Ganan Soto, Adam Mclntyre, Sungeeta Agrawal, Shara R. Bialo, and Charlotte M. Boney declare that they have no conflict of interest. Robert A. Hegele has research grants from Acasti, Amgen, Lilly, and Pfizer and receives support from the Canadian Institutes for Health Research, grant $\# 13430$. He is on the advisory boards of Amgen, Aegerion, Sanofi and Merck. None of the authors have any competing interest in this manuscript. 


\section{Authors' contributions}

AGS compiled the case and references, drafted the initial manuscript, edited, and approved the final manuscript as submitted. SA contributed to the case report section and compiling references, reviewed and revised the manuscript, and approved the final manuscript as submitted. SRB contributed to the discussion section and compiling references, reviewed and revised the manuscript, and approved the final manuscript as submitted. AM and $\mathrm{RH}$ performed the genomic DNA analysis on the subjects, drafted the genomic DNA analysis section, edited and approved the final manuscript as submitted. CMB reviewed and revised the manuscript, and approved the final manuscript as submitted.

\section{Acknowledgments}

We thank Dr. Chanika Phornphutkul for her assistance with genetic testing.

\section{Author details}

${ }^{1}$ Department of Pediatrics, Rhode Island Hospital and Brown University, Providence, RI, USA. ${ }^{2}$ Robarts Research Institute, Western University, London, ON, Canada. ${ }^{3}$ Baystate Children's Hospital, 759 Chestnut Ave S584, Springfield, MA, USA

Received: 3 August 2015 Accepted: 26 August 2015 Published online: 04 September 2015

\section{References}

1. Evans V, Kastelein JJ. Lipoprotein lipase deficiency-rare or common? Cardiovasc Drugs Ther. 2002;16:283-7.

2. Brunzell JD. Familial Lipoprotein Lipase Deficiency. 1999 Oct 12 [Updated 2014 Apr 24]. In: Pagon RA, Adam MP, Ardinger HH, et al., editors. GeneReviews ${ }^{\circledast}$ [Internet]. Seattle (WA): University of Washington, Seattle; 1993-2014. Available from: http://www.ncbi.nlm.gov/books/nbk1308/ ?report=reader

3. Rahalkar AR, Giffen F, Har B, Ho J, Morrison KM, Hill J, et al. Novel LPL mutations associated with lipoprotein lipase deficiency: two case reports and a literature review. Can J Physiol Pharmacol. 2009;87:151-60.

4. Feoli-Fonseca JC, Lévy E, Godard M, Lambert M. Familial lipoprotein lipase deficiency in infancy: clinical, biochemical, and molecular study. J Pediatr. 1998;133:417-23

5. Gaudet D, Methot J, Kastelein J. Gene therapy for lipoprotein lipase deficiency. Curr Opin Lipidol. 2012;23:310-20.

6. Emi M, Wilson DE, Iverius PH, Wu L, Hata A, Hegele R, et al. Missense mutation (Gly__ Glu188) of human lipoprotein lipase imparting functional deficiency. J Biol Chem. 1990;265:5910-6.

7. Davies BS, Beigneux AP, Fong LG, Young SG. New wrinkles in lipoprotein lipase biology. Curr Opin Lipidol. 2012;23:35-42.

8. Wion KL, Kirchgessner TG, Lusis AJ, Schotz MC, Lawn RM. Human lipoprotein lipase complementary DNA sequence. Science. 1987;235:1638-41.

9. Chen TZ, Xie SL, Jin R, Huang ZM. A novel lipoprotein lipase gene missense mutation in Chinese patients with severe hypertriglyceridemia and pancreatitis. Lipids Health Dis. 2014;13:52.

10. Mailly F, Palmen J, Muller DP, Gibbs T, Lloyd J, Brunzell J, et al. Familia lipoprotein lipase (LPL) deficiency: a catalogue of LPL gene mutations identified in 20 patients from the UK, Sweden, and Italy. Hum Mutat. 1997; 10:465-73

11. Mohandas MK, Jemila J, Ajith Krishnan AS, George T. Familial chylomicronemia syndrome. Indian J Pediatr. 2005;72:181.

12. Zahavi A, Snir M, Kella YR. Lipemia retinalis: case report and review of the literature. J AAPOS. 2013;17(1):110-1.

13. Rosenson RS, Shott S, Tangney CC. Hypertriglyceridemia is associated with an elevated blood viscosity Rosenson. Atherosclerosis. 2002;161:433-9.

14. Yuan G, Al-Shali KZ, Hegele RA. Hypertriglyceridemia: its etiology, effects and treatment. CMAJ. 2007;176:1113-20.

15. Santamarina-Fojo S. The familial chylomicronemia syndrome. Endocrinol Metab Clin North Am. 1998;27:551-67

16. Kawashiri MA, Higashikata T, Mizuno M, Takata M, Katsuda S, Miwa K, et al. Long-term course of lipoprotein lipase ( $L P L)$ deficiency due to homozygous $\mathrm{LPL}$ (Arita) in a patient with recurrent pancreatitis, retained glucose tolerance, and atherosclerosis. J Clin Endocrinol Metab. 2005;90:6541-4.
17. Ellis D, Orchard TJ, Lombardozzi S, Yunis EJ, McCauley J, Agostini R, et al. Atypical hyperlipidemia and nephropathy associated with apolipoprotein E homozygosity. J Am Soc Nephrol. 1995;6:1170-7.

18. Blackett P, Tryggestad J, Krishnan S, Li S, Xu W, Alaupovic P, et al. Lipoprotein abnormalities in compound heterozygous lipoprotein lipase deficiency after treatment with a low-fat diet and orlistat. J Clin Lipidol. 2013;7:132-9.

19. DeVita RJ, Pinto S. Current status of the research and development of diacylglcerol O-acyltransferase 1 (DGAT1) inhibitors. J Med Chem. 2013;56:9820-5.

\section{Submit your next manuscript to BioMed Central and take full advantage of:}

- Convenient online submission

- Thorough peer review

- No space constraints or color figure charges

- Immediate publication on acceptance

- Inclusion in PubMed, CAS, Scopus and Google Scholar

- Research which is freely available for redistribution

Submit your manuscript at www.biomedcentral.com/submit 